\title{
The Kanehira-Hatusima 1940 Collection of New Guinea Plants X
}

\author{
R. Kanehira \& S. Hatusima: Monimiaceae.
}

Received.March 20, 1942.

Kibara warenensis Kanehira et Hatusima, sp. nov. Fig. 1.

Frutex glaberrimus 1-2 m. altus, ramuli subteretes ad nodos dilatati, circ. $4 \mathrm{~mm}$. crassi. Folia opposita, coriacea, oblanceolato-oblonga vel oblonga, apice brevissime acuminata vel acuta, basi rotundato-cuneata vel rotundata, margine argute spinuloso-denticulata, saltem infra médium repandato-denticulata vel subintegra, $18-27 \mathrm{~cm}$. longa, $5.2-8.2 \mathrm{~cm}$. lata, in sicco utrinque opaca, pallide flavo-viridescentia, nervis lateralibus utrinsecus 7 vel 8 , sub angulo $60^{\circ}-80^{\circ}$ a costa divergentibus, cum venis reticulatis supra leviter subtus prominente elevatis, glabris. Inflorescentiae axillares ad nodos fasciculatae, glabrae, breviter cymosae, circ. $1 \mathrm{~cm}$. longae, bracteae parvae, ovato-lanceolatae, acutae, glabrae; flores $\hat{o}$ flavescentes, pedicellati, pedicello, $6-10 \mathrm{~mm}$. longo, glabro, apicem versus \pm incrassato, receptaculum cupuliforme $1.8 \mathrm{~mm}$. longum, $2 \mathrm{~mm}$. latum, carnosum, glabrum, quam tepala multo longiore, tepala 6, perparva, cruciatim opposita, membranacea; stamina 6 , inaequilonga, glabra in receptaculo conferta, compresso-ovoidea, circ. $1 \mathrm{~mm}$. longa. Drupae ellipsoideae circ. $1.5 \mathrm{~cm}$. longae $1 \mathrm{~cm}$. latae, in receptaculo lignoso recurvato circ. $2 \mathrm{~cm}$. diam. confertae.

No. 14245 Kanehira-Hatusima, Momi, about 60 miles south of Manokwari, April 19, 1940. In high rain forests at about $100 \mathrm{~m}$. altitude.

This may be contrasted with Kibara oliviformis BECC. which has much broader leaves with more numerous lateral nerves and much larger olivaceous fruits.

Levieria montana Becc. Malesia 1 (1877) 192 ; Perkins in Enal. Pflanzenr. Heft 4 (1901) 21, ibid. Heft 49 (Nachtr.) (1911) 9, et EngL. Bot. Jahrb. 52 (1914) 197. Fig. 2.

No. 13821 Kanehira-Hatusima, Iray, near the Lake Giji, Angi, April 8,1940 , in thickets at about $1,900 \mathrm{~m}$. altitude, a small tree, $6 \mathrm{~m}$. high, fruits orange-coloured. No. 13514 Kanehira-Hatusima, the same locality, April 10, 1940, in mossy forests.

Distrib. Amboina.

Undescribed fruits of this species are follows: Drupae anguste ovoideae, 


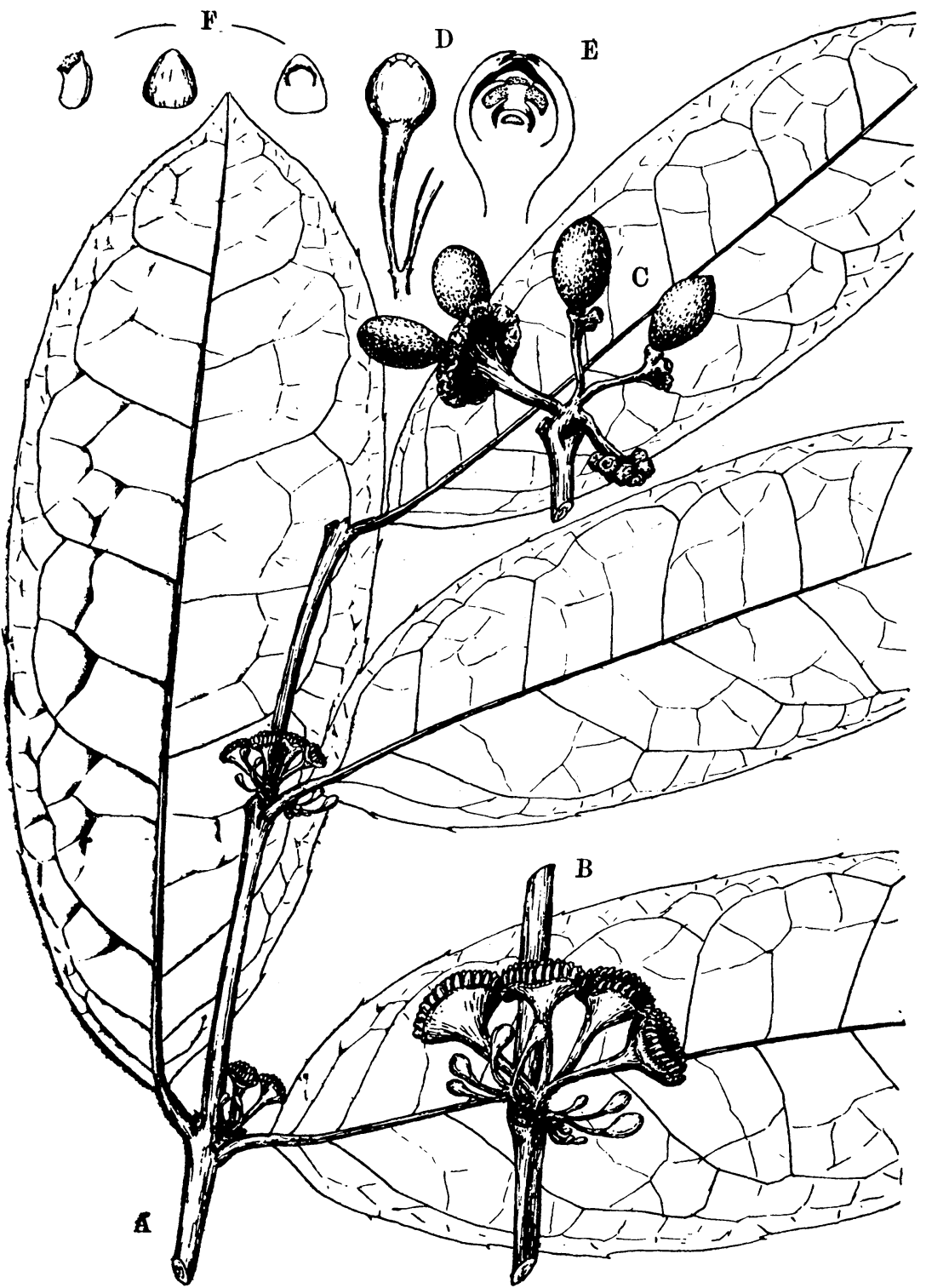

Fig. 1. Kibara warenensis KAN. et HAT.

A Flowering branchlet $\times 2 / 3$. B Inflorescence $\times 1 \frac{1}{3}$. C Infructescence $\times 2 / 3$.

$\mathrm{D}$ of flower. $\mathrm{E}$ The same in l.s. $\mathrm{F}$ Stamens, seen from different sides.

circ. $8 \mathrm{~mm}$. longae, $5 \mathrm{~mm}$. latae, glabrae, subsessiles, in receptaculo paullo incrassato, margine reflexo $7-8 \mathrm{~mm}$. diametro insidentes.

No. 13821 slightly differs from the description of the type in having nearly entire leaves. 


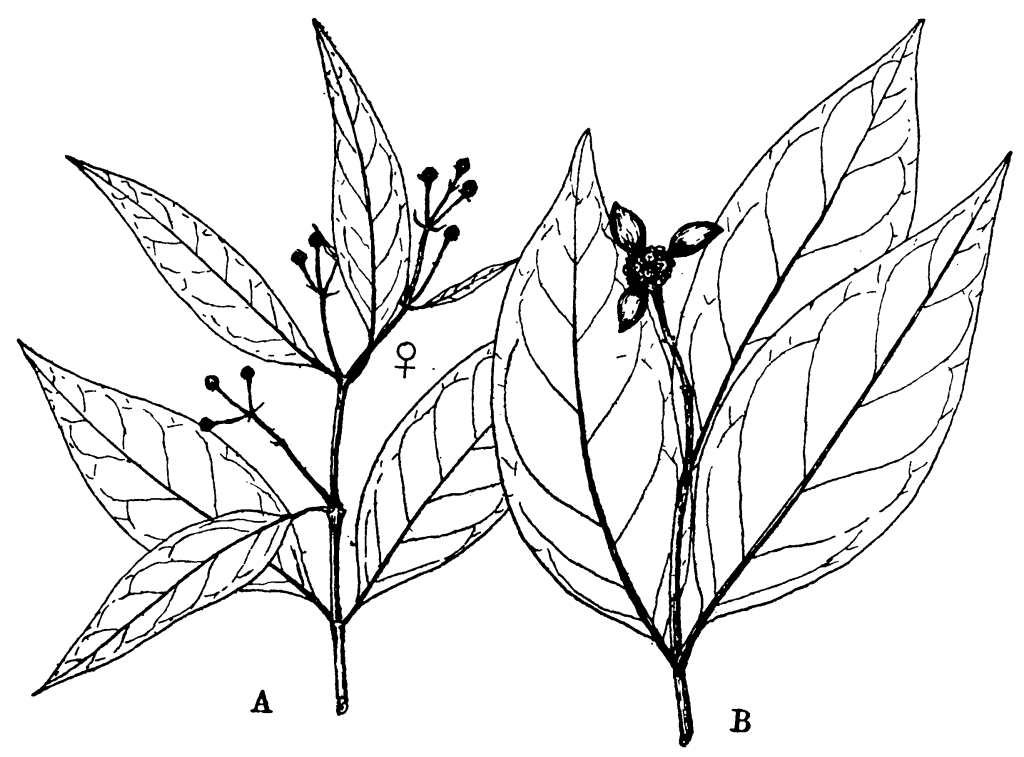

Fig. 2. Levieria montana BECC.

A Flowering branchlet (no. 13514) $\times 2 / 3$. B Fruiting branchlet $\times 2 / 3$.

Palmeria acuminata Kanehira et Hatusima sp. nov., Fig. 3, F-G.

Frutex scandens, rami ramulique cinereo-purpurascentes, glabri, juniores ad apicem stellato-pilosi, mox glabrescentes. Folia opposita, firme coriacea, oblonga vel oblongo-lanceolata vel oblongo-elliptica, $2.5-4 \mathrm{~cm}$. longa, 1-1.7 cm. lata, apice breviter acuminata, basi rotundato-cuneata vel cuneata, margine integra, deorsum anguste recurvata, utrinque glabra, supra \pm bullata, nervis lateralibus utrinsecus 4 vel 5 , arcuatim adscendentibus, ante marginem inter sese curvato conjugatis ut costa subtus sparsissime pallide fusco-stellato-pilosis, venis reticulatis subdistinetis, utrinque leviter impressis, petiolo 2-3 $\mathrm{mm}$. longo, piloso. Inflorescentiae $\hat{o}$ paniculatae axillares 1-2.5 cm. longae, pilis cinereo-flavescentibus dense obtectae, pedicello circ. $1 \mathrm{~mm}$. longo, receptaculum plane cupuliforme, extus tomentosum, intus hirsuto-tomentosum, circ. $1.6 \mathrm{~mm}$. diametero, tepala 4 vel 5 , ovata, apice obtuse acuta, induplicato-valvata, stamina numerosa, perparva, filamentis subnullis.

No. 13665 KaneHira-Hatusima, Angi, April 16, 1940. In low spinneys on the summit of Mt. Koebre at about 2,200 m. altitude; scandent.

This is most closely related to Palmeria parvifolia $\mathrm{K}_{\mathrm{AN}}$. et $\mathrm{H}_{\mathrm{AT}}$., from which it differs by its much thicker and larger glabrous leaves with acuminate apices, and in its longer panicles. This may also be contrasted with Palmeria arfakiana BECc. which has much larger leaves with obtuse apices. 


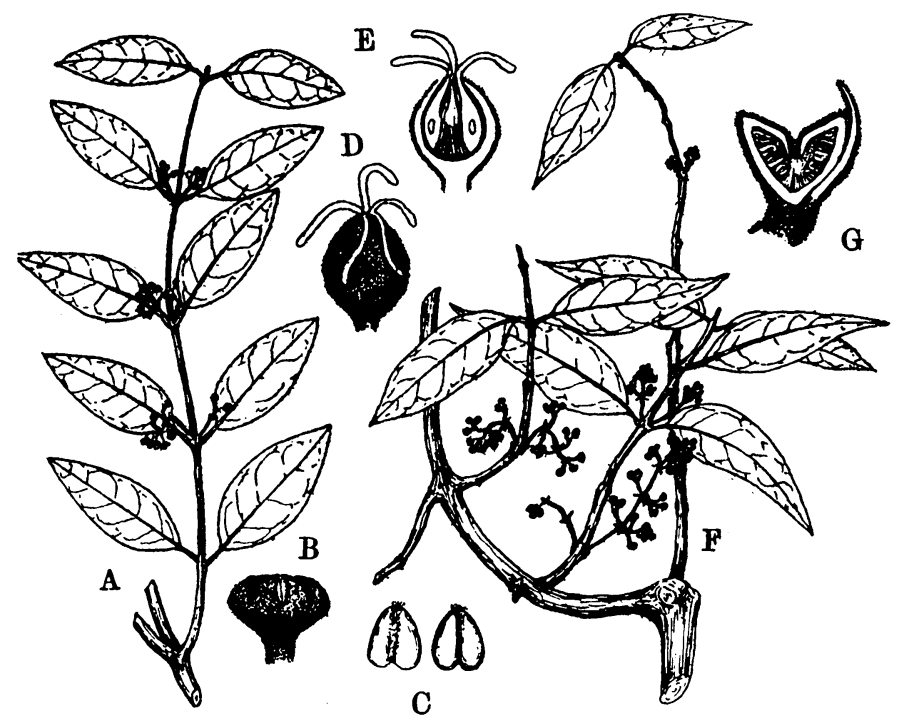

Fig. 3. Palmeria parvifolia KAN. et HAT. (A-E), Palmeria acuminata KAN. et HAT. (F-G).

A Flowering branchlet (no.13575, of) $\times 2 / 3$. B male flower. C Stamens, seen from different sides. D Female flower (no. 14101). E The same in long. section. F Flowering branchlet (no. 13665, $\delta$ ) $\times 1 / 2 . \quad$ G Male flower in long. section.

Palmeria angica Kanehira et Hatusima sp. nov. Fig. 4, C-G.

Frutex scandens ad 2-3 $\mathrm{m}$. altus, rami ramulique brunneo-nigrescentes densiuscule breviter tomentelli. Folia opposita, petiolo 5-7 mm. longo 1.5-2 $\mathrm{mm}$. crasso, tomentello, oblongo-elliptica, chartaceo-coriacea, 4-8 cm longa, $2-4 \mathrm{~cm}$. lata, basi rotundata, apice brevissime acuminata, supra opaca, initio densiuscule mox sparse stellato-pilosa, subtus dense stellato-pilosa, nervis lateralibus utrinsecus 5, prope marginem arcuatim adscendentibus, ut costa supra vix subtus prominente elevatis, venis reticulatis subtus valde elevatis, supra obsoletis. Infructescentiae axillares laxe ramosae ad $10 \mathrm{~cm}$. longae, rhachis pedicellique cinereo-stellato-tomentosa. Receptaculum $q$ (post anthesin) urceollatum ad $2.5 \mathrm{~mm}$. longum, extus brevissime cinereo-tomentosum, intus sericeo-hirsutum, apice leviter 5-lobum, earpella 7 vel 8 , in receptaculo inclusa, stylis filiformibus, glabris, tepala paullo superantibus. Drupae subglobosae circ. $7 \mathrm{~mm}$. diam. extus brevissime cinereo-stellatotomentosae. Semina subglobosa, circ. $5 \mathrm{~mm}$. longa, testa ossea.

No. 13630 Kanehira-Hatusima, Angi, April 6, 1940. In low spinneys on the burnt open summit of Mt. Koebre at about 2,300 m. altitude; scandent. 
This is most elosely related to Palmeria arfakiana BEcc. from which it differs chiefly by its oblong pubescent leaves, prominently reticulated

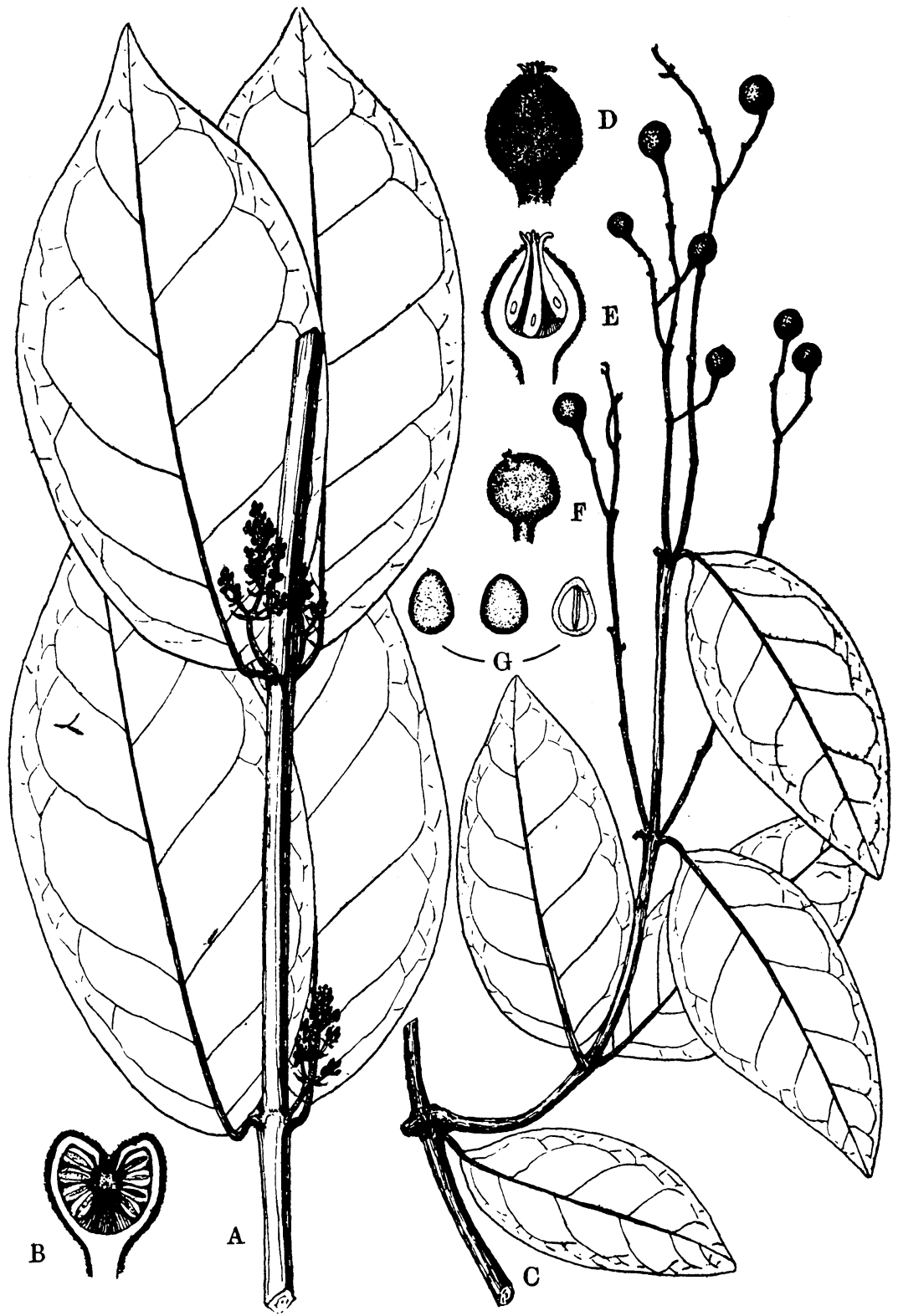

Fig. 4. Palmeria dallmannensis KAN. et HAT. (A-B), Palmeria angica Kan. et Hat. (C-G).

A Flowering branchlet $\times 2 / 3$. B Male flower in 1.c. $\mathrm{C}$ Fruiting branchlet $\times 2 / 8$. D $q$ flower. E The same in 1.s. F Fruit $\times 1 \frac{113}{3}$. G Seeds. 
beneath, somewhat longer fruiting cymes, and smaller fruits covered with grayish tomentum and much smaller seeds.

Palmeria arfakiana Becc. Malesia 1 (1877) 186; Perkins in Engl. Pflanzenr. Heft 4 (1901) 65, fig. 18, L. M. et EnaL. Bot. Jahrb. 52 (1914) 215 ; GibBs, Contr. Phyt. \& Fl. Arfak Mts. (1917) 135; Sмгтн in Journ. Arnold Arb. 22 (1941) 245.

No. 13630 (fr.) Kanehira-Hatusima, Angi, April 6, 1940. In low spinneys on the open summit of Mt. Koebre at about 2,200 m. altitude; scandent.

Distrib. Endemic; the type was from Hatam, Arfak Mts.

Palmeria dallmannensis Kanehira et Hatusima sp. nov. Fig. 4, A-B.

Frutex alte scandens, ramuli cinerascentes, angulato-tetragoni ad apicem dense stellato-puberulis mox glabrescentes, circ. $3 \mathrm{~mm}$. crassi, internodiis 4-6 cm. longis. Folia petiolata, petiolo 7-8 $\mathrm{mm}$. longo, obovatoelliptica ve loblongo-elliptica, coriacea, $10-13 \mathrm{~cm}$. lata, apice breviter acuminata, basi cuneato-rotundata, margine integra, supra primo sparse cinereostellata et papillosa mox glabra, subtus primo brevissime cinereo-tomentosa mox tomentella, nervis lateralibus utrinsecus 6 vel 7 , ant marginem inter sese curvatis ut costa supra vix subtus prominente elevatis, venis reticulatis supra obsoletis, subtus leviter subdistinctis. Inflorescentiae $\hat{o}$ paniculatae, ad $3 \mathrm{~cm}$. longae, brevissime cinereo-tomentosae, bracteis foliaceis, lanceolatis, maxima ad $4 \mathrm{~cm}$. longis, pedunculo ad $1 \mathrm{~cm}$. longo, $1 \mathrm{~mm}$. crasso, pedicelli $1 \mathrm{~mm}$. longi, receptaculum plane cupuliforme, extus cinereo-tomentosum, intus dense pallide fusco-hirsutum, stamina $\infty$, perparva.

No. 12005 Kanehira-Hatusima, Dallmann, about $45 \mathrm{~km}$. inward of Nabire, March 1, 1940. In Agathis-forests at about $500 \mathrm{~m}$. altitude, scandent.

This is distinguished from the all allied species by its sharply 4-angled branchlets and by its larger obovate to elliptic-obovate leaves with grayish tomentum beneath. This may be contrasted with P. incana A. C. Sм.

Palmeria parvifolia Kanehira et Hatusima sp. nov. Fig. 3, A-E.

Frutex scandens circ. 2-3 m. altus, rami ramulique fusco-purpurascentes, teretes, ramuli teretes cinereo-stellato-tomentelli ad $1 \mathrm{~mm}$. crassi. Folia opposita, firme coriacea, $1.5-2.8 \mathrm{~cm}$. longa, $0.7-1.5 \mathrm{~cm}$. lata, elliptica vel ovato-elliptica, apice acuta vel obtuse acuta, basi cuneata vel cuneatorotundata, supra glabra, sub lente sparse stellato-pilosa vel glabra, costa media supra impressa, subtus prominente elevata, densiuscule stellatopuberula, nervis lateralibus utrinsecus 4 vel 5 , tenuis, venis reticulatis 


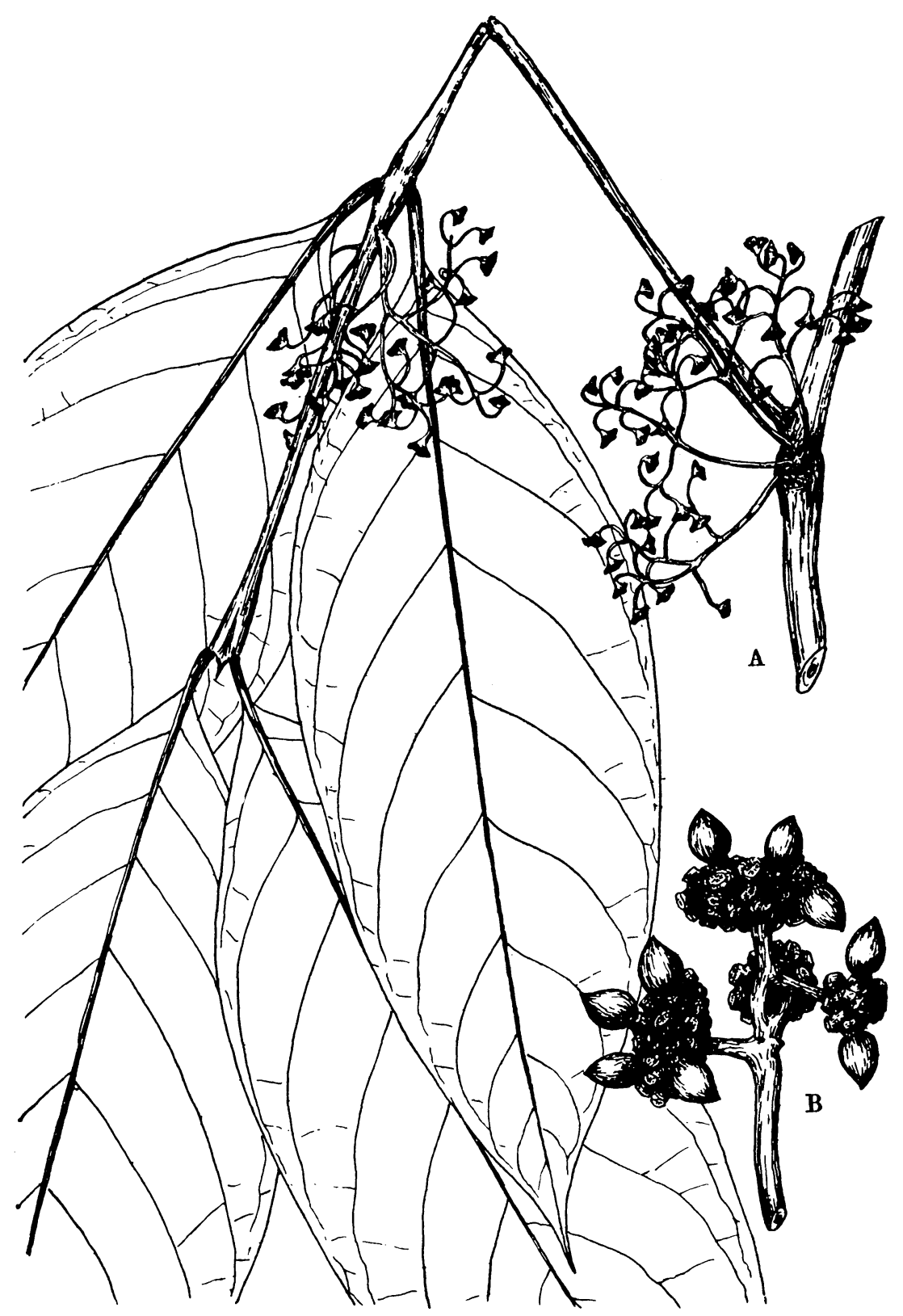

Fig. 5. Steganthera hospitans (BECc.) KAN. et HAT.

A Flowering branchlet $\times 2 / 3$. B Infructescence $\times 2 / 3$. 
utrinque distinctis et impressis, petiolo ad $3 \mathrm{~mm}$. longo, dense stellatopuberulo. Inflorescentiae ô axillares, racemosae, ad $7 \mathrm{~mm}$. longae, cinereotomentosae, bracteis lanceolatis circ. $0.8 \mathrm{~mm}$. longis suffultae, flores $\hat{o}$ parvi circ. $1.2 \mathrm{~mm}$. diamtero, pedicello $1.5-2 \mathrm{~mm}$. longo, receptaculum plane cupuliforme extus cinereo-tomentosum, tepala 4 , rarius 5 , triangulari-ovata, apice obtusa, induplicato-valvata, extus cinereo-tomentella, stamina numerosa, antherae ovatae, apice obtusae, $0.3 \mathrm{~mm}$. longae, connectivo dorso cinereo-piloso, filamentis subnullis. Flores o urceolati ad $1.2 \mathrm{~mm}$. lati, $1.5 \mathrm{~mm}$. alti, extus brevissime cinereo-tomentosi, intus dense sericeo-hirsuti, pedicellati (pedicellis circ. $1.5 \mathrm{~mm}$. longis), apice leviter 4-lobi, stylis filiformibus \pm recurvatis, glabris, tepala valde superantibus circ. $1.5 \mathrm{~mm}$. longis.

Nos. 14061 ( $q$ type), 13575 ( $\delta$ type) Kanehira-Hatusima, Angi, April 6,1940 . In low spinneys on the open summit of Mt. Koebre at about 2,300 m. altitude, scandent.

This is well characterized by its small leaves and inflorescences, and very small flowers with very long glabrous styles. The nearest alliance of the species may be with Palmeria montana SмIтH which has pubescent leaves with acuminate apices, longer inflorescences bearing larger flowers with more numerous carpels (10-15). In the character of the leaves this may also be contrasted with Palmeria arfakiana BEcc.

Steganthera* hospitans (Becc.) Kanehira et Hatusima comb. nov. Fig. 5. Kibara hospitans BECC., Malesia 1 (1877-1883) 189.

Anthobembix hospitans PerK. in ENGL. Bot. Jahrb. 25 (1898) 567, ibid. 52 (1914) 205, fig. 4.

No. 12345 Kanehira-Hatusima, Patema, about $40 \mathrm{~km}$. inward of Nabire, March 5, 1940. In edge of rain-forests at about $400 \mathrm{~m}$. altitude; a small tree, $3 \mathrm{~m}$. high, rare.

Distrib. Eastern New Guinea.

* The fact that certain species such as Steganthera insignis, S. Brassii and $S$. riparia have trumpet-shaped female receptacles so similar to those of Anthobembix that the separation of these two genera are quite difficult when the female flowers only are known and also that the difference in the shape of the male receptacles is not so remarkable, suggests us to transfer all species of the Anthobembix to the Steganthera.

Steganthera Moszkowskii (PERK.) comb. nov.

Anthobembix Moszkowskii Perk. in Engl. Pflanzenr. 4, 101 (Nachtr.) (1911) 26 et EngL. Bot. Jahrb. 52 (1914) 203.

Distrib. Western New Guinea.

Steganthera Ledermannil (BECc.) comb. nov.

Anthobembix Ledermannii Perk. in Engl. Bot. Jahrb. 52 (1914) 203, f. 3.

Distrib. North western New Guinea. 
Steganthera oligocarpella Kanehira et Hatusima sp. nov. Fig. 6.

Frutex $1 \mathrm{~m}$. altus, glaberrimus, squarrosus, rami subteretes, rugulosi, ramuli 1-1.2 mm. crassi, glabri, in sicco nigrescentes. Folia opposita, oblonga, plerumque $2-2.5 \mathrm{~cm}$. longa, $7-8 \mathrm{~mm}$. lata, maxima $2.8 \mathrm{~cm}$. longa, $9 \mathrm{~mm}$. lata, firme coriacea, apice obtusa, basi anguste cuneata, margine integra utrinque glaberrima, nervis lateralibus 3 vel 4; ut venis reticulatis supradeviter subtus prominente elevatis. Petiolo $2 \mathrm{~mm}$. longo. Inflorescentiae brevissime racemosae, supra axillas foliorum ortes vel axillares, foliis breviores, 3-5-flores rarius solitares, glabrae, basi bracteatae, rhachis $3 \mathrm{~mm}$. longa, glabra; flores $\hat{o}$ pedicellati, pedicello $6-7 \mathrm{~mm}$. longo, apicem versus sensim incrassato, receptaculum carnosum, urceolatum circ. $2 \mathrm{~mm}$. crassum, $2.5 \mathrm{~mm}$. altum, glabrum, apice brevissime 4-dentatum, carpella 2-3 erecta, oblonga; -flores 우 circ. $2 \mathrm{~mm}$. diamtero, pedicello circ. $6 \mathrm{~mm}$. longo, glabro ; receptaculum urceolatum, tepala 4 , perparva, imbricata ; stamina 3-4, filamentis latis,

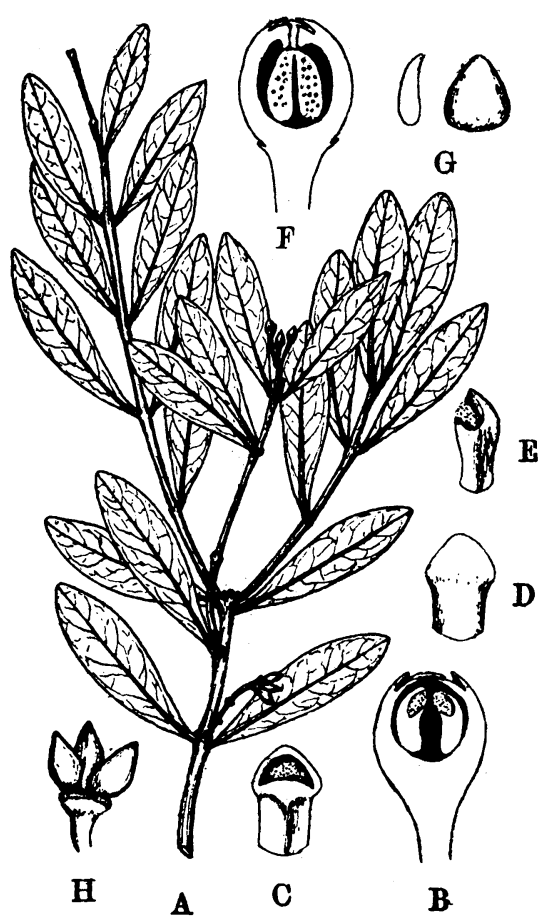

Fig. 6. Steganthera oligocarpella KAN, et HAT.

A Branehlet with flowers and fruits $\times$ \%3. $B$ of flower in long. section. C-E Stamens, seen from different sides. $F$ \& flower in long. section. $G$ ovaries, seen from different sides. $\mathrm{H}$ carpels $\times 3$.

brevibus, glabris; antherae loculis confluentibus rima horizontali semiorbiculari dehiscentibus. Drupae ovoideae, apice acutae, glabrae, circ. $3 \mathrm{~mm}$. longae, $2 \mathrm{~mm}$. latae, conplures in receptaculo disciformi, lignoso, circ. $3 \mathrm{~mm}$.

Steganthera parvifolia (PERK.) comb. nov.

Anthobembix parvifolia Perk. in Enar. Bot. Jahrb. 52 (1914) 205.

Distrib. North-eastern New Guinea.

Steganthera dentata (VALETON) comb. nov.

Anthobembix dentata Valeton in Bull. Depart. Agr. Ind. Neerl. 10 (1907) 13; Perk. in ENaL. Bot. Jahrb. 52 (1914) 207.

Distrib. South-western New Guinea.

Steganthera oligantha (PERK.) comb. nov.

Anthobembix oligantha PeRK. in ENGL. Bot. Jahrb. 25 (1898) 568.

Distrib. South-eastern New Guinea. 
lato, glabro, congestae.

No. 13975 Kanehira-Hatusima Angi, April 9, 1940. In edge of low spinneys on the open summit of Mt. Koebre at about 2,300 m. altitude.

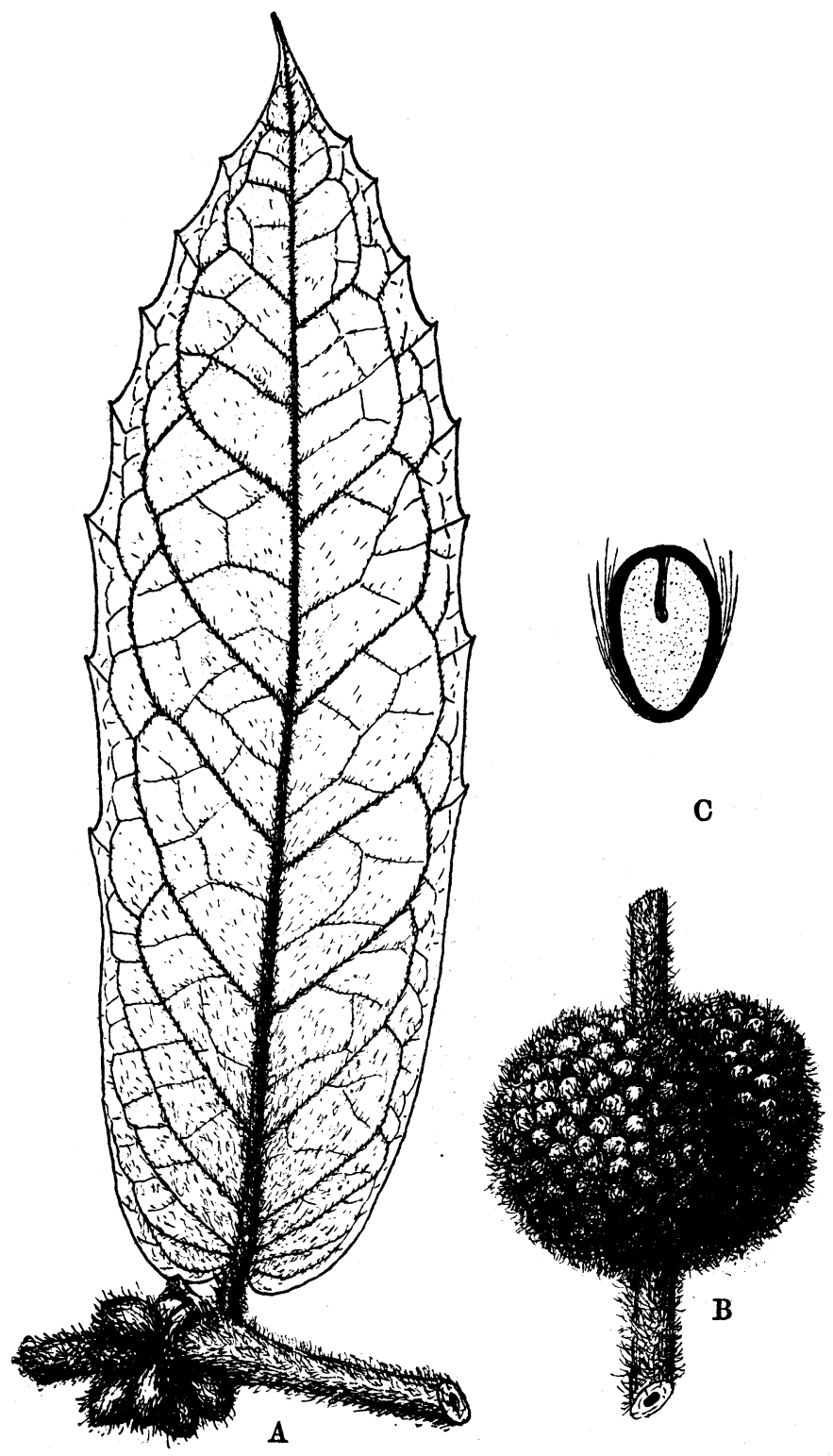

Fig. 7. Steganthera villosa KAN. et HAT.

A Fruiting branchlet $\times 1 / 2$. B Young infructescence $\times 2 / 3$. C Seed in long. section $\times 1^{1 / 3}$. 
This is well characterized by its very small, oblong and glabrous leaves with obtuse apices and prominently elevated veins beneath, its small inflorescences, and by its few carpels and stamens in the ovoideous receptacles. This may be contrasted with S. Schumanniana PERK. which has much larger leaves.

\section{Steganthera villosa Kanehira et Hatusima sp. nov. Fig. 7.}

Frutex $2 \mathrm{~m}$. altus, ramuli juniores subteretes, $5-8 \mathrm{~mm}$. crassi, pilis fuscescentibus, 4-5 mm. longis, patentibus densissime obtecti mox villosuli. Folia opposita, 24-44 cm. longa, 6.5-13 cm. lata, chartaceo-coriacea, apice caudatim acuminata (caudiis $2-2.5 \mathrm{~cm}$. longis), basi cordata, margine supra medium remote acuteque denticulata, supra primo yilis circ. $3 \mathrm{~mm}$. longis sparse subtus densiuscule obtecta, supra mox glabra, nervis lateralibus utrinsecus 12 vel 13 , ut venis reticulatis supra impressis, subtus prominente elevatis, dense pilosis. Petiolo 5-6 mm. longo, $2 \mathrm{~mm}$. crasso, fusco-villosulo. Flores ignoti. Infructescentiae axillares, subsessiles, circ. $5 \mathrm{~cm}$. diamtero. Drupae obovoideae, numerosae, sessiles, $1.5 \mathrm{~cm}$. longae $1 \mathrm{~cm}$. latae, extus longe hirsutae, in receptaculo lignoso revoluto circ. $2.5 \mathrm{~cm}$. diam. confertae.

No. 13150 Kanehira-Hatusima, Momi, about 60 miles south of Manokwari, March 28, 1940. In rain-forests on a limestone hill at about $500 \mathrm{~m}$. altitude.

This is most closely related to S. insculpta Perk. from which it differs by its larger oblong leaves with cordate bases, and its larger obovoideous fruits.

Steganthera riparia Kanehira et Hatusima sp. nov. Fig. 8.

Arbuscula 4-5 m. alta ; ramuli subteretes ad nodos complanato-dilatati, 4-5 mm. crassi, initio cinereo-pilosi, mox glabrescentes. Folia opposita, petiolo 1.2-2 cm. longo, 1.5-2 mm. crasso, cinereo-piloso, oblonga vel oblongooblanceolata, 16-28 cm. longa, 6-11 cm. lata, apice obtuse acuta vel obtuse breviter acuminata, basi cuneato-rotundata, chartacea, supra glabra, subtus dense pilosa, mox glabrescentia, nervis lateralibus 6-8, arcuatim adscendentibus ut costa supra sparse, subtus dense pilosa. Inflorescentiae axillares laxe paniculatae, 5-8 cm. longae, rami paniculae 1-1.2 $\mathrm{cm}$. longi in cymas plurifloras exeuntes, pedunculatae, pedunculo $3-5 \mathrm{~cm}$. longo, tomentello. Flores ô circiter $3 \mathrm{~mm}$. diametero, $2 \mathrm{~mm}$. alti, pedicello circ. $5 \mathrm{~mm}$. longo, tomentello, receptaculum obconico-turbinatum, carnosum, extus cinereotomentellum, apice 4-lobum, tepalis 4, perbrevis, stamina 4, in receptaculi medio adpressa, circ. $0.5 \mathrm{~mm}$. longa et lata, dorso anticeque sericea, antherarum loculis thecum apicalem horizontalem rima introrsa dehiscentem formantibus; flores $\%$ circ. $3 \mathrm{~mm}$. diametro, pedicellati, pedicello 5-8 


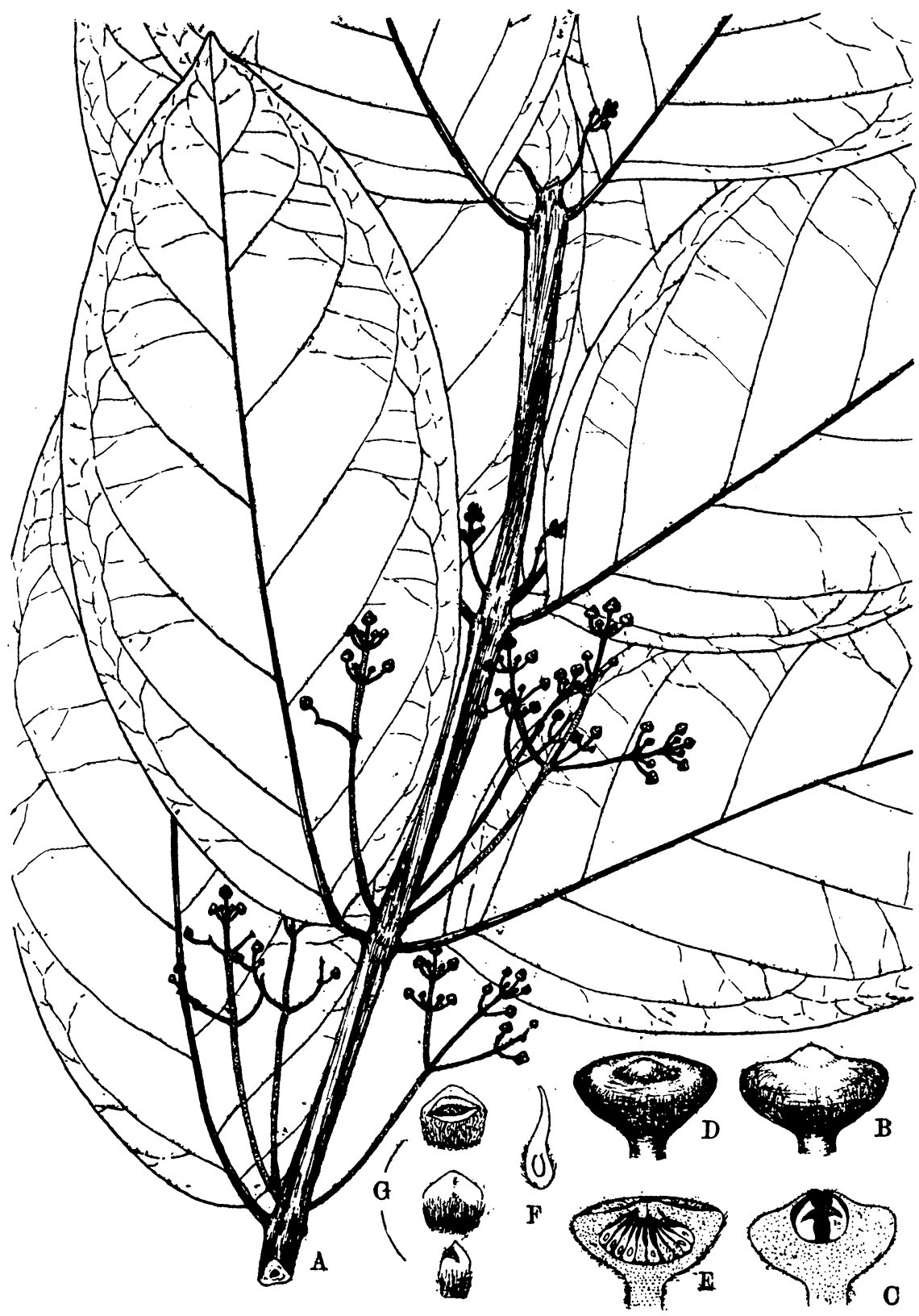

Fig. 8. Steganthera riparia KAN. et HAT.

A Flowering branchlet $\times 2 / 3 . \quad$ B of flower $\times 7 . \quad$ C The same in l.s. $\times 7$. D o flower $\times 7$. E The same in 1.s. $\times 7 . \quad$ F Ovary. G Stamens, seen from different sides. 
em. longo, einereo-tomentoso ; receptaculum obovato-turbinatum, apice concavum vel si mavis truncato-exsculptum, marginibus acutis, rigide coriaceum, basin versus crassum, extus parce fusco-pilosum; carpella numerosa, in disco sessilia, multiseriata, infra medium sericea, stylis subulatis glabris.

No. 12669 Kanehira-Hatusima, Slieber, about $40 \mathrm{~km}$. inward of Nabire, March 9, 1940. This is closely related to Steganthera insignis Perk. from which it is readily distinguished by its much smaller flowers.

Steganthera Brassii (Sм.) comb. nov. Fig. 9.

Anthobembix Brassii A. C. Sмiтh in Journ. Arn. Arb. 22 (1941) 239.

No. 13927 Kanehira-Hatusima, Angi, April 8, 1940. In mossy forests along Iray River pouring to the Lake Giji at about $1900 \mathrm{~m}$. altitude. A shrub, $2 \mathrm{~m}$. high.

Distrib. Eastern Dutch New Guinea.

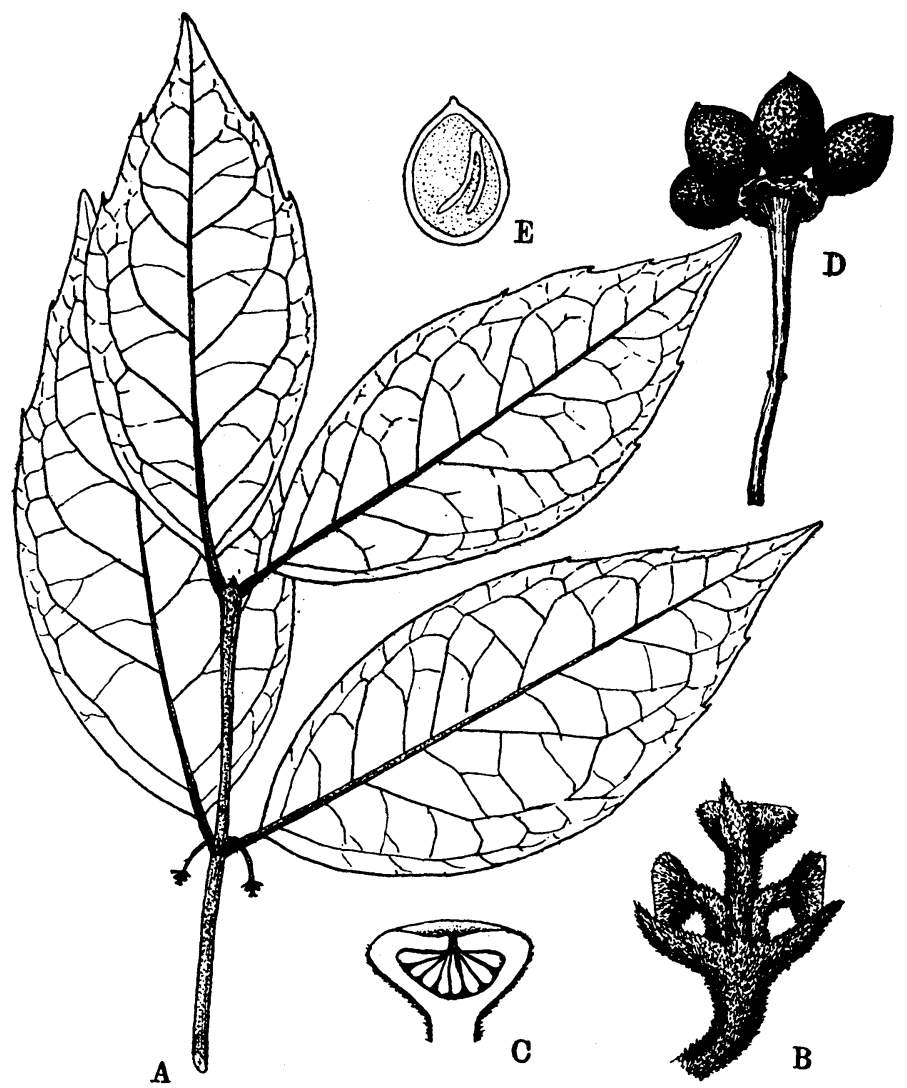

Fig. 9. Steganthera Brassii (SM.) KAN, et HAT. (no. 13927).

A Flowering branchlet $\times 2 \%$. B Inflorescence. $\mathrm{C}$ \% flower in long. section.

D Fruits $\times 1$. E Seed in long. section $\times 1 \frac{1}{3}$. 
Trimenia arfakensis GIßBS, Contr. Phytog. \& Fl. Arfak. Mts. (1917) 136. Ad descriptionem addenda: Drupae globosae circ. $3-4 \mathrm{~mm}$. diametro, nigrae.

No. 13450 Kanehira-Hatusima, Angi, April 5, 1940, in thickets on the eastern ridge of the Lake Gita at about 2,200 m. altitude; No. 14051 Kanehira-Hatusima, the same locality, April 9, 1940, in low spinneys on the open summit of Mt. Koebre at about 2,200 m. altitude; a small tree, 4-6 m. high. Fig. 10.

Distrib. Celebes.

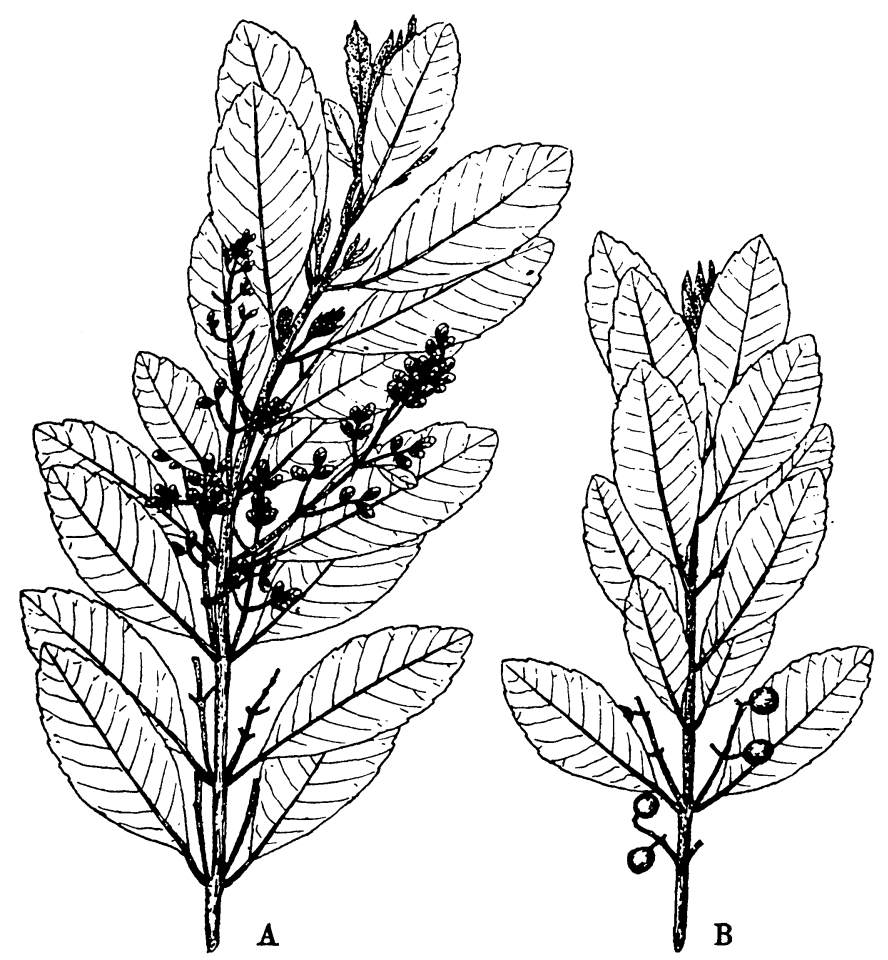

Fig. 10. Trimenia arfakensis GiBBS.

A Flowering branchlet (no. 14051) $\times 2 / 3$. B Fruiting branchlet (no. 14051) $\times 2 / 3$. 


\title{
金平・初息探某ニニーギニヤ植物研究 $\mathbf{X}$
}

\author{
金本亮三・初島 任彦
}

\section{モニミア科}

摘 要

本科入種數カラ云へバ南米二最モ多イガ, ソノ分化發達ノ點カラ見レバ印度, 馬 來地方二劣ツテキル。殊ニニニーギニヤデハ最モョク分化發達シ現今迄 7 猲䄪 60 種 ガ知ラレ，本地域ガ印度，馬來二於ケル分布ノ中心地タルコトハ疑ナイトコロデア ル。今包我々ガ探集シタ本科植物ハ 5 偈 13 種郎チ Kibara (1 種), Palmeria (5 種), Leviera (1 種), Steganthera (5.種), Trimenia (1 種) ゙゙, 內 8 種八末記錄ノ新種デ アツタ。而シテ 13 種中 7 種ハ海拔 2000 米內外ノAngi 湖一帶二限ラレテキル事貝 カラ考へ今後末踏查ノ高地帶カラ佾多數ノ新種/發見ガ期待出來ヨウ。

以下今包發見シタ特記スベキ種類二就キ略述スル。

Kibara warenensis K. et H. ワーレン附近ノ丘陵地帶ノ森林內ニ見ラレル 2 米內 外ノ灌木デ，全株無毛，大キナ葉卜，疎ナ刺毛狀ノ鋸齿

Palmeria parvifolia K. et H. アンキ湖附近ノ尾根通リノ疎林內二多イ。高サ 2 〜3 米/熦雄異株ノ蔓性灌木デ從來知ラレタ本屬中最モ葉ノ小サイ種類デアラウ。 一番近イノ八最近藩領ニューキニヤノ東部カラ記載セラレタ P. montana SM. デア ル。

Palmeria acuminata K. et H. 本種モアンキ湖附近ノ產デ一見前者二似テキルガ 葉八稍大キク, 先端八長ク尖リ, 花序八著シク大キイノデ一見區別出來ル。前者二 比シ稍稀デアル。

Palmeria angica $\mathrm{K}$. et $\mathrm{H}$. 本種モアンギ湖附近ノ库デ一見同地方二普通ナ $P$. arfakiana BECC. =近イガ葉形，葉脉习異ニシ，果賽モ小サイ。

Palmeria dallmannensis K. et H. ダルマン地方ノ林緣二見ラレル高サ 4〜5米ノ 蔓デ，小枝ガ四角形フ呈シタ特徵アル種類デアル。最モ近イノハP. incana SM. デ アル。

Steganthera hospitans (BECC.) K. et H.

本種八本科ノ專門家 PERKINS 女史ニヨリAnthobembix 目二入レラレテキタガ, 今 回我々八種々研究ノ結果, 從來舉げラレタ Steganthera トAnthobembix トノ區別 點ハ显ヨ分ツ程重要ナモノデナイト考へタノデ後者二最スル種類ヨ全部Steganthera 二移シタ。

Steganthera oligocarpella K. et H. アンギ湖附近ノ尾根ノ疎林內二稀産スル高 サ 1 米內外/灌木デ，葉ガ本屬卜シテハ極メテ小サク，花床中 $=2 \sim 3$ 個ノ心皮シカ 有シナイノガ特特デアル。

Steganthera villosa $\mathrm{K}$. et $\mathrm{H}$. ワーレン北方ノ石灰岩ノ山デ探集シタ高サ 2 米位 ノ灌木デ，葉ガ非常二大キク，葉，小枝二長イ䄉毛ガ密生シテキルノガ特徵デアル。 
最初 Kibara 易卜考へテキタガ一般的樣子カラ (花八無イガ) 考へ Steganthera 昌 入レルコトニシタ。

Steganthera riparia K. et H. ナビレ奥宅探集シタ 小喬木デ St. insignis PERK. 二最モ近イガ花八著シクホサイノデー見區別出來ル。

Steganthera Brassii (SM.) K. et H.

本標本ノ重複品ハアーノルド樹木園二寄贈シタガ, ソノ標本ョ見ダ A. C. SмITH 氏八最近同氏甘記载シタAnthobemibix Brassii A. C. SM. ト同一物ラシイトノ通信 ガアツクガ，原跑载文ト一致シナイ所ガアリ且我ネ/探集品モ完全ナモノデナイノ ぞ果シテ同一物カ將來ノ研究二侯チタイ。

Trimenia arfakensis GIBBs.

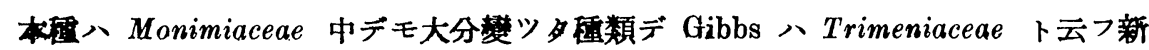
科迄創定シタコトガアルガ，其後 SCHLECHTER，㼛究ず Monimiaceae - 合併サレ

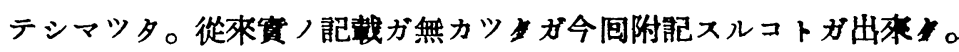

